\title{
INTEGRASI PEMBELAJARAN PENDIDIKAN AGAMA ISLAM DENGAN \\ WAWASAN KEBANGSAAN DI SMAN 2 KOTA TANGERANG SELATAN
}

\author{
Budi Mulia \\ Universitas Pamulang \\ dosen01549@unpam.ac.id
}

Naskah diterima: 25 Maret 2020, direvisi: 28 April 2020, disetujui: 2 Juli 2020

\section{Abstrak}

Mengembangkan kemampuan dan membentuk watak serta peradaban bangsa yang bermartabat dalam rangka mencerdaskan kehidupan bangsa, bertujuan untuk berkembangnya potensi peserta didik agar menjadi manusia yang beriman dan bertakwa kepada Tuhan Yang Maha Esa, berakhlak mulia, sehat, berilmu, cakap, kreatif, mandiri, dan menjadi warga negara yang demokratis serta bertanggung jawab merupakan fungsi dari pendidikan nasional. Hal ini sejalan dengan Armai Arif bahwa pendidikan agama Islam sebagai suatu proses pengembangan potensi kreatifitas peserta didik, bertujuan untuk mewujudkan manusia yang beriman dan bertakwa kepada Allah SWT., cerdas, trampil, memiliki etos kerja yang tinggi, berbudi pekerti luhur, mandiri dan bertanggung jawab terhadap dirinya, bangsa dan negara serta agama. Proses itu sendiri telah berlangsung sepanjang sejarah kehidupan manusia

Pendekatan penelitian kualitatif digunakan dengan menggambarkan secara umum tentang pembelajaran bermakna pendidikan agama Islam Selanjutnya pendekatan analisis dilakukan untuk mengetahui lebih jauh tentang bagaimana model pembelajaran bermakna pendidikan agama Islam yang dipergunakan pada sekolah tersebut. Data-data yang diperoleh kami himpun dalam satu susunan serta diinterpretasikan sehingga mendapat kesimpulan dari sasaran obyek yang diteliti. denganObjek Penelitian Sekolah Menengah Atas Negeri 2 (SMAN 2) Kota Tangerang Selatan , teknik Pengumpulan Data.

Hasil dari sebuah penanaman wawasan kebangsaan minimal masingmasing pribadi siswa dapat memahami dan menghayati arti dari cinta kepada bangsa dan tanah air.

Kata Kunci: Wawasan Kebangsaan, PAI 


\section{PENDAHULUAN}

Dewasa ini muncul pertanyaan mengapa akhir-akhir ini wawasan kebangsaan menjadi lebih banyak dipersoalkan. Apabila kita coba mendalaminya, menangkap berbagai ungkapan masyarakat, terutama dari kalangan cendekiawan dan pemuka masyarakat, memenag mungkin ada hal yang menajdi keprihatinan, Pertama, ada kesan seakan-akan semangat kebangsaan telah menjadi dangkal atau tererosi terutama di kalangan generasi muda seringkalai disebut bahwa sifat materialistic mengubah idealism yang merupakan jiwa kebangsaan. Kedua, ada kekuatiran ancaman disintegrasi kebangsaan, dengan melihat gejala yang terjadi di berbagai negara, terutama di negara-negara berpenduduk mayoritas beragama Islam seperti di Suriah dan Palestina. Melalui isu perebutan kekuasaan dan pembangkangan yang berakibat pertumpahan darah. Hal ini yang menjadi sorotan dimana paham kebangsaan merosot menjadi keusukuan dan keagamaan. Ketiga ada keprihatinan tentang adannya upaya untuk melarutkan pandangan hidup bangsa pada pola pikir yang asing untuk bangsa ini. Dengan demikian nilai-nilai wawasan kebangsaan menjadi penting dalam menjaga dan mempertahankan kebhinekaan dan persatuan bangsa.

Mengembangkan kemampuan dan membentuk watak serta peradaban bangsa yang bermartabat dalam rangka mencerdaskan kehidupan bangsa, bertujuan untuk berkembangnya potensi peserta didik agar menjadi manusia yang beriman dan bertakwa kepada Tuhan Yang Maha Esa, berakhlak mulia, sehat, berilmu, cakap, kreatif, mandiri, dan menjadi warga negara yang demokratis serta bertanggung jawab merupakan fungsi dari pendidikan nasional.' Hal ini sejalan dengan Armai Arif bahwa pendidikan agama Islam sebagai suatu proses pengembangan potensi kreatifitas peserta didik, bertujuan untuk mewujudkan manusia yang beriman dan bertakwa kepada Allah SWT., cerdas, trampil, memiliki etos kerja yang tinggi, berbudi pekerti luhur, mandiri dan bertanggung jawab terhadap dirinya, bangsa dan negara serta agama. Proses

${ }^{1}$ Undang-undang nomor 20 tahun 2003 Tentang Sistem Pendidikan Nasional pasal 3, (Jakarta: Fokus Media), h. 62 
itu sendiri telah berlangsung sepanjang sejarah kehidupan manusia. ${ }^{2}$

Dalam menangapi

tujuan

pendidikan yang membentuk akhlak/moral diperlukan wawasan kebangsaan yang didalamnya terdapat nilai-nilai luhur yang dapat dimiliki oleh setiap siswa-siswi. Melalui kebangsaan dapat meminimalisir sikap yang menyimpang yan dapat merugikan negara secara umum.

Selain itu terdapat dalam artikel yang tersebar di media elektronik ${ }^{3}$, menyimpulkan bahwa adanya kecenderungan asyarakat tidak peduli terhadap pancasila yang meruakan sebuah gejala munculnya sikap apatisme yag dilatarbelakangi oleh minimnya keteladanan di kalangan elite. Pernyataan tersebut diungkapkan oleh Prof. Armaidy Armawi, M.Si Guru Besar Fakultas Filsafat Universitas Gadjah Mada dalam pidato pegukuhan jabatan Guru Besar UGM di ruang Balai Senat UGM, Selasa, 15 Desember 2015,berikut ini:

“Tidak ada satu kata dan peruatan serta minimnya keteladanan di kalangan elite. Pancasila hanya dijadikankonsep yang dihafalkan, bukan

${ }^{2}$ Armai Arief, Pengatar Ilmu dan Metodologi Pendidikan Islam, (Jakarta: Ciputat Pers, 2002), h. 3

${ }^{3} \mathrm{http} / /$ ugmac.id yang ditulis oleh Gusti tanggal 15 Desember 2015 nilai-nilai yang harus dipedomani karena mereka tidak mampu menyelami Pancasila"

Indikasi-indikasi lunturnya nilainilai wawasan kebangsaan di kalangan generasi muda merupakan salah satu akibat dari pengaruh negatif globalisasi dan mengkhawatirkan eksistensi suatu negara. Hal ini menuntut kewaspadaan kita bersama, karena jika jiwa dan semangat kebangsaan dari suatu bangsa telah hilang, maka pada hakikatnya eksistensi dari bangsa dan negara yang bersangkuan telah tidak ada. Walaupun secara administratif bangsa dan negara masih berdiri. ${ }^{4}$

Dengan demikian konsep yang terkandung dalam nilai-nilai wawasan kebangsaan yang terdapat dalam pembelajaran agama Islam dapat mengoptimalkan perilaku baik terhadap bangsa dan negara.

SMA Negeri 2 Kota Tangerang Selatan merupakan sekolah menengah atas yang memiliki segudang prestasi akademik dan prestasi non akademik. Hal ini ditandai dengan manajemen yang berbasis kepada sistem dan pengelolaan tata tertib yang terpantau oleh sekolah melalui walikelas. SMAN 2 Kota Tangering Selatan dalam kualitas lulusan terbaik se Indonesia pada tahun 2015 dan mendapat penghargaan dari

\footnotetext{
${ }^{4}$ martidirjo: 2008:1
} 
presiden republik Indonesia melalui kementrian pendidikan dan kebudayaan. Dengan demikian SMAN 2 Kota Tangerang Selatan perlu dilakukan penelitian berkaitan dengan wawasan kebangsaan melalui pendidikan agama Islam. Hal ini penting dilakukan mengingat wawasan kebangsaan sudah mulai luntur dimakan oleh arus teknologi dan informasi yang setiap hari semakin memprihatikan pengaruhnya terhadap jati diri bangsa

Oleh karenanya peran serta dan fungsi implementasi nilai-nilai wawasan kebangsaan agar selalu diingatkan dan dilakukan dalam kehidupan sehari-hari.

\section{METODE}

Pendekatan penelitian kualitatif digunakan dengan menggambarkan secara umum tentang pembelajaran bermakna pendidikan agama Islam Selanjutnya pendekatan analisis dilakukan untuk mengetahui lebih jauh tentang bagaimana model pembelajaran bermakna pendidikan agama lslam yang dipergunakan pada sekolah tersebut. Data-data yang diperoleh kami himpun dalam satu susunan serta diinterpretasikan sehingga mendapat kesimpulan dari sasaran obyek yang diteliti. denganObjek Penelitian Sekolah Menengah Atas Negeri 2 (SMAN 2) Kota Tangerang Selatan , teknik Pengumpulan Data
Penelitian kualitatif yang digunakan dalam penelitian ini memiliki ciri-ciri sebagai berikut: (1) menggunkan pengukuran kualitatif terhadap data atau informasi yang dikumpulkan, (2) data kualitatif berbentuk deskripsi rinci tentang situasi, orang, kejadian, interaksi dan tingkah laku yang diamati, khususnya yang berkaitan dengan situasi yang mendukung tentang metode pembelajaran bermakna pendidikan Agama Islam. (3) deskripsi rinci tersebut mennyangkut tujuan madrasah, siswa, pendidik, isi/materi, alat pendidikan, situasi lingkungan

\section{Sumber Data}

Sumber data terdiri dari dua bagian yaitu data primer dan data sekunder. Data primer meliputi dokumen profil sekolah yang memuat visi, misi serta bahan pembelajaran, pengamatan/Observasi yang dimulai dari proses pembelajaran di kelas yang didalamnya termasuk RPP dan kegiatan ekstra kurikuler. ${ }^{5}$, Wawancara ${ }^{6}$ dilakukan

5 Observasi merupakan teknik pengamatan dan pencatatan sistematis dari penomena-penomena yang diselidiki. Observasi dilakukan untuk menemukan data dan informasi dari gejala atau fenomena (kejadian atau peristiwa) secara sistematis dan didasarkan pada tujuan penyelidikan yang telah dirumuskan. Lihat. Mahmud, Metode Penelitian Pendididkan, (Bandung: Pustaka Setia, 2011), h.168

Wawancara adalah teknik pengumpulan data dengan mengajukan pertanyaan kepada responden dan mencatat 
kepada guru PAl, kepala sekolah, wakil kep ala sekolah bidang kurikulum, wakil kepala sekolah bidang kesiswan dan siswa. Sedangkan data sekunder diambil dari buku perpusakaan,jurnal atau bahan ajar.Sumber data tersebut diolah melalui teknik triangulasi.

HASIL DAN PEMBAHASAN

Wawasan Kebangsaan Di Sekolah

Makna Wawasan Kebangsaan

Menurut Otho H. Hadi pada judul Nation and Character Building melalui pemahaman Wawasan Kebangsaan bahwa Secara ringkas persamaan di atas dapat dijelaskan bahwa pertambahan yang dapat dicapai pada pertumbuhan ekonomi sesungguhnya sangat tergantung pada upaya pemberdayaan ekonomi dan interaksi antara peranan kelembagaan untuk mengatasi konflik sosial yang terjadi. Peranan kelembagaan dapat dijelaskan antara lain dengan eksistensi birokrasi yang bersih, bebas KKN, pranata hukum yang berwibawa dengan penegakan hukum yang konsisten dan sebagainya. Sementara itu, latent sosial conflik dapat dijelaskan antara lain dengan besarnya ketidak-merataan (inequality) yang terjadi di dalam masyarakat. Di samping itu pluralitas

atau merekam jawaban-jawaban responden. Lihat. Mahmud, Metode Penelitian Pendidikan, (Bandung: Pustaka Setia, 2011), h. 173 seperti beragamnya suku, budaya daerah, agama, dan berbagai aspek politik lainnya, serta kondisi geografis negara kepulauan yang tersebar, juga merupakan bagian dari latent sosial conflict.

Makna Wawasan kebangsaan terdapat lima makna wawasan kebangsaan bagi Indonesia yang memiliki keragaman dalam hal agaman, atnik, suku bangsa, adat istiadat, sosial budaya, ekonomi, politik. Pertama, wawasan kebangsaan mengamanatkan kepada seluruh bangsa Indonesia agar menenpatkan persatuan dan kesatuan, kepentingan serta keselamatan bangsa diatas kepentingan individu ataupun golongan. Kedua, wawasan kebangsaan tidak memberi tempat pada patriotism yang sempit dan picik. Ketiga, wawasan kebangsaan mengembangkan persatuan Indonesia sedemikian rupa sehingga ajudkan bangsa Bhineka Tunggal lka dipertahankan.Keempat, NKRl yang merdeka, bersatu, berdaulat adil dan makmur bertekad untuk mewujudkan bangsa yang maju. Kelima, wawasanm kebangsaan yang dilandasi oleh falsafah hidup pancasila. Bangsa Indonesia telah berhasil merintis jalan dalam menjalani ditengah-tengah tata kehidupan bangsabangsa di dunia.

Nilai dasar wawasan Kebangsaan terdapat enam nilai yang 
fundamental untuk kokohnya NKRl, yaitu: Pertama, penghargaan terhadap harkat dan martabat manusia sebagai makhluk ciptaan Tuhan Yang Maha Esa.Kedua, cinta terhadap tanah air dan bangsa. Ketiga, demokrasi atau kedaulatan rakyat, Keempat, Tekad untuk kehidupan kebangsaan yang bebas merdeka dan bersatu. Kelima, masyarakat yang adil dan makmur, Keenam, kesetiakawanan sosial.

Tujuan dari pendidikan berwawasan kebangsaan meliputi, antara lain sebagai berikut:

a. Meningkatkan pengertian, pemahaman, dan persepsi yang tepat tentang persatuan dan kesatuan antar sesama warga NKRl.

b. Menanamkan jiwa kepemimpinan dan tanggung jawab sebagai penerus Bangsa Indonesia.

c. Mengembangkan kepekaan sosial, solidaritas, toleransi, dan saling mengenal serta saling menolong antar sesama warga NKRI walaupun berbeda latar belakang.

Maka dirasa perlu materi pendidikan berwawasan kebangsaan yang diintegrasikan dalam materi pelajaran diberbagai jenjang pendidikan, baik formal maupun non-formal. Adapun materinya sebagai berikut:

a. Cinta Tanah Air.
Setiap peserta didik harus mencintai tanah air sebagai ruang hidup dalam menjalankan kehidupannya yang selalu mendapat ancaman baik dari dalam maupun luar negeri,antara lain: diwujudkan menjaga lingkungan hidup, mengenal wilayah tanah air, dan mencintai produk dalam negeri agar tumbuh rasa nasionalisme. Sehingga, kesadaran bertanah air satu, tanah air Indonesia menjadi semangat bersama bagi semua peserta didik.

b. Kesadaran Berbangsa dan Bernegara. Peserta didik harus dituntut untuk mempunyai kesadaran atas tanggung jawabnya sebagai masyarakat yang didukung pengetahuan, keterampilan, kompetensi serta pribadi manusia yang beriman, sehat, cakap, kreatif, mandiri, dan bersikap demokratis, antara lain diwujudkan dengan bersikap disiplin, bertanggung jawab, saling menghargai dan menghormati, menjaga kerukunan, berjiwa gotong royong, mendahulukan kewajiban dari pada hak sebagai warga negara, serta mendahulukan kepentingan negara dan bangsa dari pada kepentingan pribadi dan kelompok. Sehingga peserta didik mampu menyadari atas kemajemukan yang ada dalam bangsa ini dan melekat 
dalam jiwa-jiwa sanubari, baik suku,ras, agama dan budaya sebagai bagian dari pada kehidupan berbangsa dan bernegara.

c. Pancasila Sebagai Ideologi Negara.

Pancasila adalah dasar ideologi negara yang sah, dan tidak ada ideologi lain. Ketentuan ini adalah hal yang ini. Nilai-nilai ajaran yang ada pada pancasila harus dimasukkan dalam lini materi pelajaran. Sehingga mampu mewujudkan tatanan peserta didik yang mengacu dan berlandaskan ideologi Pancasila,antara lain diwujudkan dengan bertaqwa kepada Tuhan YME, menjalankan kewajiban agama, mempunyai kesadaran membantu sesama, memelihara persatuan dan kesatuan, mengedepankan musyawarah untuk mufakat, serta mewujudkan keadilan sosial. Dengan materi seperti ini, semua peserta didik diberbagai jenjang pendidikan termasuk para pendidik mempunyai hak dan kewajiban melaksanakan semangat kebangsaan dan Bela Negara dalam semua aspek kehidupan. Pendidikan berwawasan kebangsaan harus berupaya membuat peserta didik menjadi senang dan riang gembira, tanpa melupakan disiplin dan tanggung jawab. Disamping itu, menggunakan bahasa-bahasa yang sederhana dan mudah dimengerti, sehingga tidak terkesan "wajib militer" dan/atau "militerisasi sipil", sehingga menakutkan. Gunakan diskusi dan praktek lapangan yang sederhana untuk mudah meresapi dan menghayati dalam pendidikan kebangsaan.

Nilai-Nilai Wawasan Kebangsaan di SMAN 2 Kota Tangerang Selatan diuraikan sebagai berikut:

1. Religius

Sikap dan perilaku yang patuh dalam melaksanakan ajaran agama yang dianutnya, toleran terhadap pelaksanaan ibadah agama lain, dan hidup rukun dengan pemeluk agama lain.

2. Jujur

Perilaku jujur bagi siswa terdapat pada tatatertib SMAN 2 Kota Tangerang Selatan, dengan demikian perilaku siswa terkontrol dengan buku tata tertib yang didalamnya memuat hak dan kewajiban peserta didik.

3. Toleransi

Sikap dan tindakan yang menghargai perbedaan agama, suku, etnis, pendapat, sikap, dan tindakan orang lain yang berbeda dari dirinya.

4. Disiplin

Disiplin merupakan tindakan yang menunjukkan perilaku tertib dan patuh 
pada berbagai ketentuan dan peraturan.

5. Kerja Keras

Kerja keras merupakan tindakan yang menunjukkan ketercapaian target dalam bekeja, penuh semangat dalam menggapai cita-cita.

6. Kreatif

Kreatif merupakan tindakan berpikir dan melakukan sesuatu untuk menghasilkan cara atau hasil baru dari sesuatu yang telah dimiliki.

7. Mandiri

Mandiri merupakan sikap dan perilaku yang tidak mudah tergantung pada orang lain dalam menyelesaikan tugastugas dengan baik.

8. Demokratis

Demokratis merupakana cara berfikir, bersikap, dan bertindak yang menilai sama hak dan kewajiban dirinya dan orang lain.

9. Sikap rasa keingintahuan yang tinggi Sikap dan tindakan yang selalu berupaya untuk mengetahui lebih mendalam dan meluas dari sesuatu yang dipelajarinya, dilihat, dan didengar.

10. Semangat kebangsaan

Semangat kebangsaan merupakan cara berpikir, bertindak, dan berwawasan yang menempatkan kepentingan bangsa dan negara di atas kepentingan diri dan kelompoknya.
11. Cinta Tanah air

Cinta tanah air merupakan ara berpikir, bertindak, dan berwawasan yang menempatkan kepentingan bangsa dan negara

12. Gemar Membaca

Gemar membaca merupakan kebiasaan menyediakan waktu untuk membaca berbagai bacaan yang memberikan kebajikan bagi dirinya.

13. Menghargai prestasi

Sikap dan tindakan yang mendorong dirinya untuk menghasilkan sesuatu yang berguna bagi masyarakat, dan mengakui, serta menghormati keberhasilan orang lain.

14. Peduli Lingkungan

Peduli lingkungan merupakan sikap dan tindakan yang selalu berupaya mencegah kerusakan pada lingkungan alam di sekitarnya, dan mengembangkan upaya-upaya untuk memperbaiki kerusakan alam yang sudah terjadi.

15. Peduli Sosial

Sikap dan tindakan yang selalu ingin memberi bantuan pada orang lain dan masyarakat yang membutuhkan.

\section{Proses Penanaman Wawasan Kebangsaan}

Penanaman wawasan kebangsaan ternyata terintegrasi pada kurikulum SMAN 2 Kota Tangerang Selatan. Adapun teknis pelaksanaan wawasan kebangsaan tersebut menurut Bambang 
melalui pembelajaran abad 2l yang didlamnya terkandung bahwa siswa mampu memiliki sikap nasionalisme yang tinggi dengan cara menyanyikan lag Indonesia Raya setiap hari, yaitu pukul 07.00. Selama menyanyikan lagu Indonesia raya seluruh arga SMAN 2 Kota Tangerang sadar untuk menghormat bendera kebangsaan Republik Indonesia. ${ }^{7}$

Sejalan dengan Nurhayati bahwa proses penanaman wawasan kebangsaan melalui upacara bendera dan menyanyikan lagu Indonesia Raya sambil menghormat Bendera. ${ }^{8}$

Penanaman wawasan kebangsaan menurut Tasrief bukan hanya melalui upacara dan menyanyikan lagu Indonesia Raya, namun harus diucapkan janji siswa yang terdapat pada buku tata tertib siswa dengan menyebutkan 'cinta tanah air dan bangsa". ${ }^{9}$

Implementasi penanaman wawasan kebangsan melalui Pendidikan Agama Islam

${ }^{7}$ Wawancara dengan Bambang Sutoyo, Wakil Kepala Sekolah bidang kurikulum tanggal 28 September 2018

${ }^{8}$ Wawancara dengan

Nurhayati, Guru Pendidikan Kewarganegaraan tanggal 28 September 2018

${ }^{9}$ Wawancara dengan Tasrief, Pembina OSIS SMAN 2 Kota Tangerang Selatan tanggal 21 September 2018
Pendidikan Agama Islam merupakan kegiatan proses belajar mengajar dengan memberikan lima aspek yang harus dijalankan, pertama, berkaitan dengan aspek alquran, aqidah, akhlak, fiqih dan tarikh Islam. Lima aspek tersebut terintegrasi pada pelajaran Pendidikan Agama Islam dan Budi Pekerti.

Implementasi penanaman wawasan kebangsaan terletak pada aspek akhlak, dimana pada aspek tersebut terdapat seni dalam berprilaku sesuai dengan $\mathrm{Al}-\mathrm{Q}$ uran dan Hadits.

Menurut Puspita, materi pelajaran yang berkaitan dengan wawasan kebangsaan dalam pendidikan agama Islam dan budi pekerti terdapat dalam Q.S Annisa ayat 59 yakni,

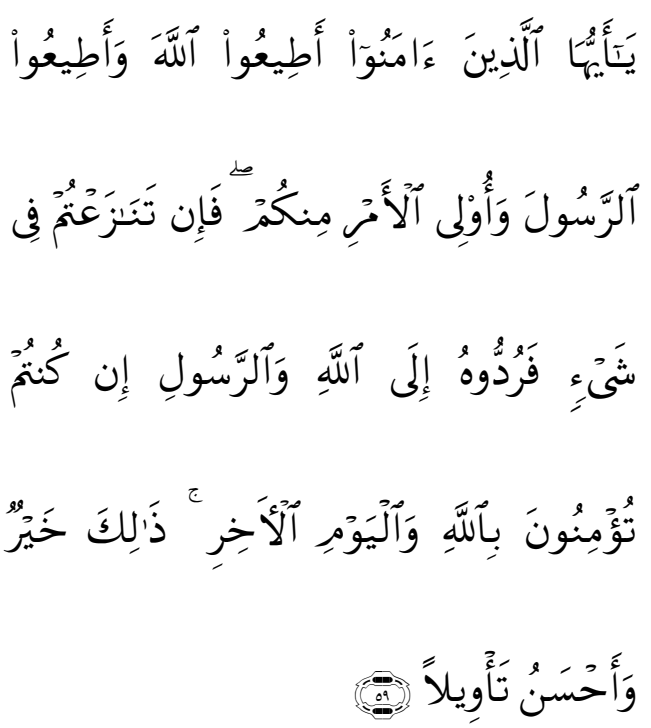

Hai orang-orang yang beriman, taatilah Allah dan taatilah Rasul (Nya), dan ulil amri di antara kamu. kemudian jika kamu berlainan Pendapat tentang sesuatu, Maka 
kembalikanlah ia kepada Allah (Al Quran) dan Rasul (sunnahnya), jika kamu benarbenar beriman kepada Allah dan hari kemudian. yang demikian itu lebih utama (bagimu) dan lebih baik akibatnya.

Pada ayat tersebut terdapat tiga poin penting yaitu tentang taat kepada ulil amri, toleransi dan kerukunan. ${ }^{10}$ Puspita melanjutkan sikap saling menghormati dan menghargai kepada sesama manusia sehingga tercipta kerukunan dan menjadi orang yang bertaqwa disertai taat kepada aturan. Berbeda dengan Nurhayati bahwa nilainilai wawasan yang ditanamkan melalui demokrasi, menghargai dan menyadari hak dan kewajiban dalam berbangsa dan bernegara.

Selain Q.S An-Nisa terdapat pula Q.S Yunus ayat 40-4l yakni:

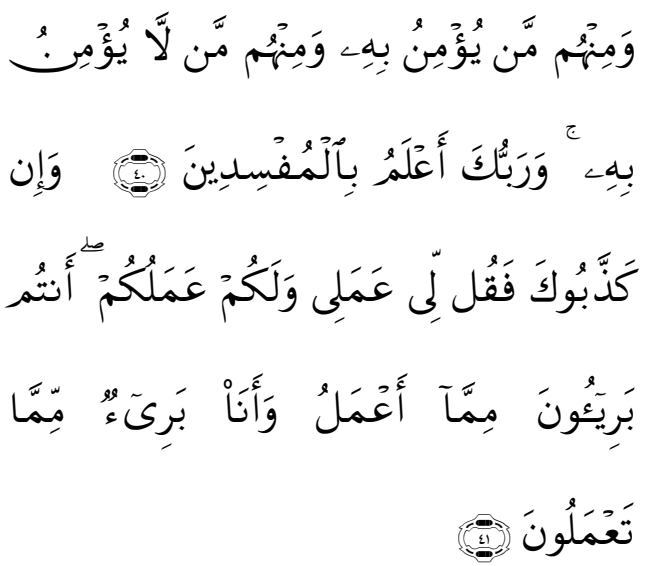

"di antara mereka ada orang-orang yang beriman kepada Al Quran, dan di antaranya ada (pula) orang-orang yang

${ }^{10}$ Wawancara dengan Puspita, guru Pendidikan Agama Islam dan Budi pekerti tanggal 25 September 2018 tidak beriman kepadanya. Tuhanmu lebih mengetahui tentang orang-orang yang berbuat kerusakan.

“ jika mereka mendustakan kamu, Maka Katakanlah: "Bagiku pekerjaanku dan bagimu pekerjaanmu. kamu berlepas diri terhadap apa yang aku kerjakan dan akupun berlepas diri terhadap apa yang kamu kerjakan".

Selain itu menurut Puspita bahwa penanaman wawasan kebangsaan dimulai dari kedisiplinan agar dapat menjadi pribadi yang memberikan keamanan dan kenyamanan untuk orang sekitar."

\section{KESIMPULAN}

Output merupakan hasil dari sebuah proses, output dari setiap kegiatan tentunya mengarah kepada kebaikan, perbaikan sikap dan tingkah laku agar menjadi manusia yang memiliki jiwa cinta tanah air dan bangsa.

Menurut Puspita, adapun output yang dihasilkan dalam penanaman wawasan kebangsaan siswa dapat memiliki jiwa bela negara yang tinggi, memiliki sikap saling menghargai antar sesama manusia. $^{12}$ Sedangkan menurut Nurhayati bahwa manfaat dari penanaman wawasan kebangsaan yaitu memiliki sikap rela berkorban untuk bangsa seseai dengan pasal 27 ayat ke

11 Wawancara dengan Puspita, guru Pendidikan Agama Islam dan Budi pekerti tanggal 25 September 2018

2 Wawancara dengan Puspita, guru Pendidikan Agama Islam dan Budi pekerti tanggal 25 September 2018 
3. Hasil dari sebuah penanaman wawasan kebangsaan minimal masingmasing pribadi siswa dapat memahami dan menghayati arti dari cinta kepada bangsa dan tanah air.

\section{DAFTAR PUSTAKA}

A.M. Saefudin, Konsep Pendidikan Agama, Sebuah Pendekatan Integratif Inovatif (Jakarta:Harian Umum Pelita, 1985)

Armai Arief, Pengatar llmu dan Metodologi Pendidikan Islam, (Jakarta: Ciputat Pers, 2002)

Asghar Ali Enginer, Devolusi Negara Islam, terj. Imam Muttaqin (Yogyakarta: Pustaka Pelajar, 2000)

Bahri Djamara, Syaiful dan Drs Aswan Zain, Strategi Belajar Mengajar, (Jakarta : Rineka Cipta, 2006)

Benny Nainggolam, Berwawasan Kebangsaan dalam Kerangka NKRI, lihat; http://www.wiziq.com/tutorial/413 89-Wawasan-Kebangsaan-Prajab111, diakses pada tanggal 08 Januari 2016.

Departemen Pendidikan Nasional, Panduan Pelaksanaan,

13 Wawancara dengan Nurhayati, Guru Pendidikan Kewarganegaraan tanggal 28 September 2018
Departemen Pendidikan Nasional,

Panduan Pelaksanaan,.

Ghufron Anik, Integrasi Nilai-Nilai Karakter Bangsa pada Kegiatan Pembelajaran,

Hasbullah. Dasar llmu Pendidikan. (Jakarta: PT Raja Grasindo Persada), 2005.

Mahmud, Metode Penelitian Pendididkan, (Bandung: Pustaka Setia, 2011)

Muhaimin, Pengembangan Kurikulum Pendidikan Agama Islam: di Sekolah, Madrasah dan Perguruan Tinggi, (Jakarta: PT Raja Grafindo Persada, 2010)

Sudirman,dkk., llmu Pendidikan. (Bandung: Remadja Karya, 1987)

Ubaidillah A. dan Abdul Rozak, Pancasila, Demokrasi, HAM, dan Masyarakat Madani, (Jakarta: Kencana Prenada Media Group, 2012)

Undang-undang nomor 20 tahun 2003 Tentang Sistem Pendidikan Nasional pasal 3, (Jakarta: Fokus Media)

Undang-undang Sistem Pendidikan Nasional, Cet. 111 (Yogyakarta: Pustaka Pelajar, 2009)

Wahid, Abdul, Pendidikan Islam Kontemporer: Problem Utama, 
Tantangan dan Prospek dalam

Ismail SM, et. Al., (Ed.),

Paradigma Pendidikan Islam,

(Yogyakarta: Pustaka Pelajar, 2001), h. 279-287

Wahid, Abdurrahman, "Nasionalisme,

Tasawwuf, dan Demokratisasi",

dalam Kompastanggal 2 April

2001.

Wawancara D\&R dengan Gus Dur,

"Politik Sebagai Moral, Bukan

Institusi" dalam Tabayun Gus Dur

(Yogyakarta: LKiS, 1998)

Zubaedi, Desain Pendidikan Karakter,

Konsepsi dan Aplikasinya dalam

Lembaga Pendidikan, (Jakarta:

Kencana Prenada Media Froup,

2011)

http://sman2tangsel.sch.id/mzr/index.php /profil/sekolah-rujukan

http://www.academia.edu/9477156/MAK

ALAH HAKIKAT PENDIDIKAN 